\title{
Nuclear Magnetic Resonance Spectra of Isobutylene- Chlorotrifluoroethylene Copolymer. II. Interpretation of Fluorine Resonances in Terms of Tetrads and Their Temperature Dependence
}

\author{
Kenkichi Ishigure, Yoneho Tabata, and Keichi Oshima \\ Department of Nuclear Engineering, University \\ of Tokyo, Tokyo, Japan. \\ (Received September 19, 1970)
}

\begin{abstract}
Proton and fluorine NMR spectra of chlorotrifluoroethylene-isobutylene copolymers with various compositions were measured. The fluorine resonances are explained in terms of tetrads, and the methyl resonances on the other hand, are interpreted in terms of triads. Not only the geminal fluorine atoms but also the geminal methyl groups were found to become nonequivalent to each other under the influence of one or two asymmetric centers in the copolymer chain. It was also found that the fluorine spectra show a marked temperature dependence in the range of 70 to $120^{\circ} \mathrm{C}$. This suggests that the copolymers have rather high potential barriers for internal rotation, probably, because of their bulky substituents. A statistical treatment was made for the polymerization process, and the results suggest that there exists a penultimate effect in this copolymerization reaction.
\end{abstract}

KEY WORDS Penultimate Effect / Markov Process / Tetrad / NMR /

Conformation / Copolymer / Isobutylene / Chlorotrifluoroethylene /

In recent years, nuclear magnetic resonance has turned out to be a powerful tool for the analysis of polymer and copolymer structures. Almost all the works, however, have been concerned with proton nuclei, and the studies of polymer structures by the measurements of fluorine resonances have been meager so far. Ferguson $^{1}$ analyzed the compositional structure of vinylidene fluoride-hexafluoropropylene copolymer by magnetic resonance of fluorine nuclei, and Naylor and Lasoski ${ }^{2}$ showed the presence of a small amount of "head to head" or "tail to tail" structures in poly(vinylidene fluoride) by the investigation of ${ }^{19} \mathrm{~F}$ NMR, which was supported by a recent detailed work. ${ }^{3}$ Tiers and Bovey ${ }^{4}$ investigated the configurational structure of polychlorotrifluoroethylene using its model compounds. Recently both proton and fluorine resonance spectra were measured of tetrafluoroethylene-isobutylene copolymers by the authors, ${ }^{5}$ and it was found that the $\mathrm{CF}_{2}$ resonances can be interpreted successfully in terms of tetrads while the proton resonances are explained by triads. The spectra of tetrafluoroethylene-iso- butylene copolymer are not too complicated to be interpreted because the material being examined as a good symmetry in structure. The spectra of chlorotrifluoroethylene-isobutylene copolymer, however, are more complicated owing to the symmetries in the polymer chain, and include quite interesting problems. In a previous paper ${ }^{6}$ proton and fluorine resonances were measured only of a copolymer of which the composition was $50: 50$, and it was confirmed spectroscopically that the copolymer has alternating structure. In the present work, the measurements were carried out at various temperatures for the copolymers deviating from the alternating structure, and a statistical treatment was made for the polymerization process.

\section{EXPERIMENTAL}

All the samples were prepared by copolymerizations of chlorotriffuoroethylene with isobutylene by means of $\gamma$-ray irradiation from a Co-60 source. The copolymerizations were carried out at $25^{\circ} \mathrm{C}$ in stainless steel vessels, and stopped at 
low conversions (12-20\%). The composition of copolymers was determined by an elemental analysis. Proton and fluorine NMR spectra were measured at $70-135^{\circ} \mathrm{C}$ using tetrachloroethylene as a solvent. A model $4 \mathrm{H}-100$ spectrometer (JEOL) was employed for the measurements of $100-\mathrm{MHz}$ (for ${ }^{1} \mathrm{H}$ ) and $94-\mathrm{MHz}$ (for ${ }^{19} \mathrm{~F}$ ) spectra.

\section{RESULTS AND DISCUSSION}

In Figure 1 is shown a typical $100-\mathrm{MHz}$ proton spectrum of a copolymer of which the composition has deviated from the alternating structure.
There appear seven sharp peaks in the region of methyl resonances, and their relative intensities are remarkably dependent on the composition of copolymers. Five of the seven peaks at the higher field are not seen in the spectrum of the alternating copolymer. A tentative assignment is given for methyl resonances on the basis of triads (tetrads for the peaks at 8.80 and at 8.85 $\tau)$ as shown in Table I. Weak resonances at 8.9 $-9.0 \tau$ are probably attributed to terminal methyl groups, though the definite assignments are not known so far.

The nonequivalence of the central methyl

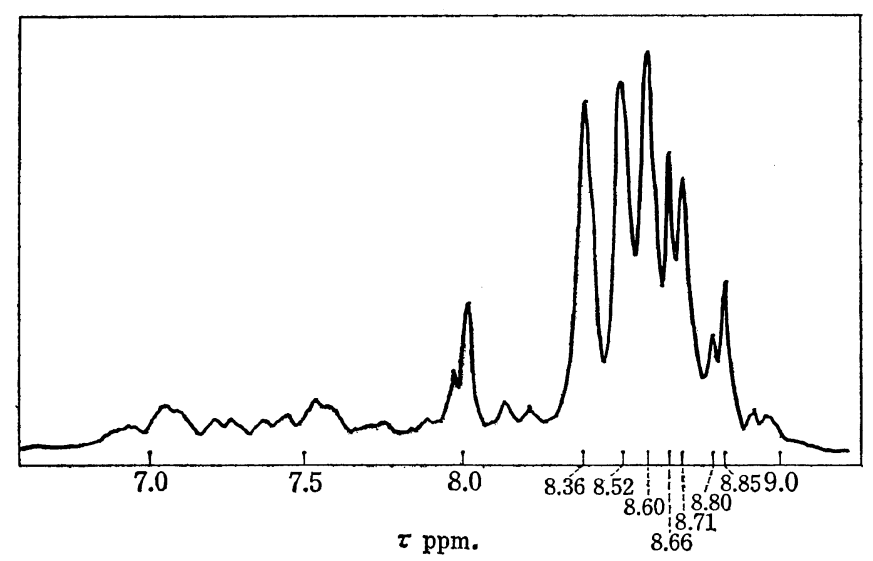

Figure 1. A $100-\mathrm{MHz}$ proton spectrum of a copolymer with $0.41 \mathrm{~mol} \%$ of CTFE at $120^{\circ} \mathrm{C}$.

Table I. Assignment of methyl resonances

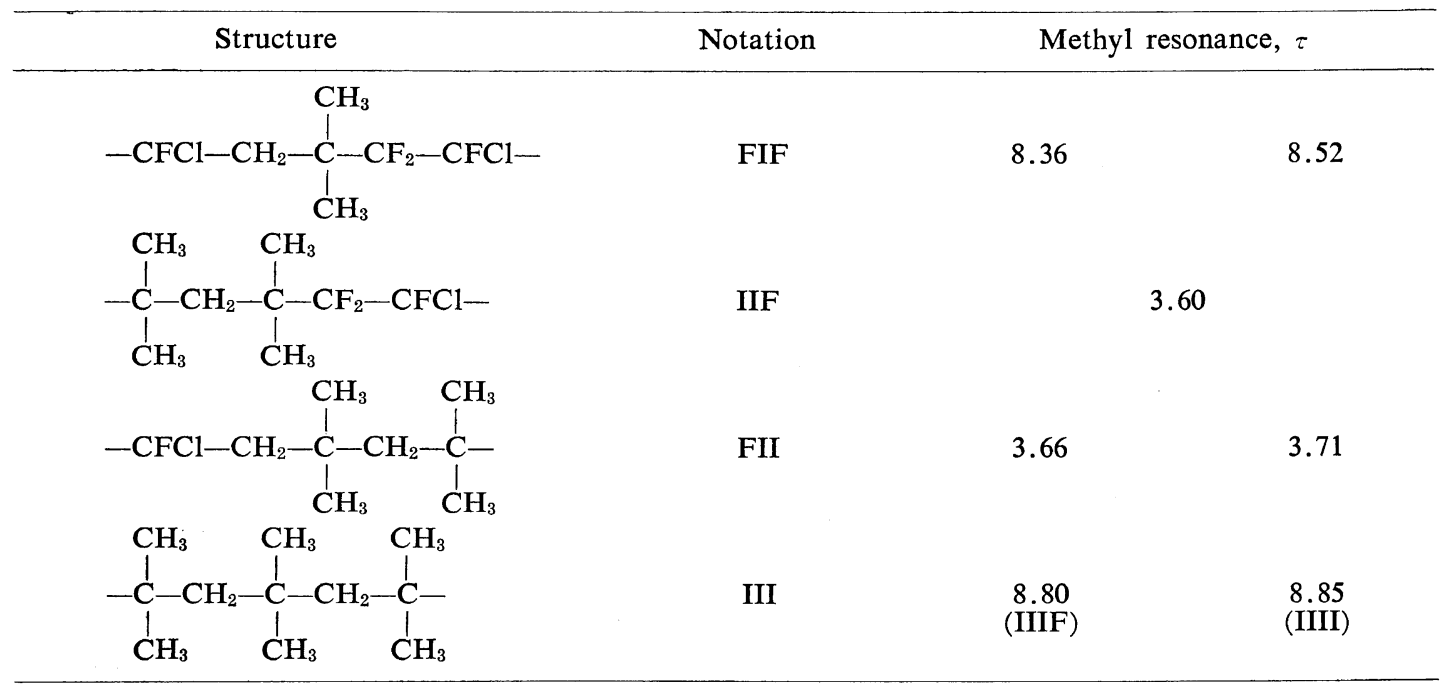


groups in the FIF triad has already been discussed in a previous paper. ${ }^{6}$ It is of great interest to consider the reason why the central methyl groups are doublets in the FII and III triads. As to the methyl resonances in the FII triad, there seem to be two possible explanations. One is the interpretation by the effect of the asymmetric carbon at a second nearest position. In the case of low molecular weight compounds, ${ }^{7,8}$ it is known from that geminal protons or geminal methyl groups become nonequivalent by the effect of an asymmetric center at the second nearest position. This may be the first example of this type of nonequivalence in polymeric systems. Another is the interpretation in terms of tetrads. If the effect of the substituents at the third nearest carbon atoms on the chemical shift of the central methyl groups is strong enough to be detected, the spectra should be analyzed on the basis of tetrads, not of triads. Consequently, the resonance assigned to the FII triad splits to two peaks attributed the FIIF and FIII tetrads. The relative intensity of these two peaks is supposed to be dependent on the composition of copolymers and the FIIF peak should be stronger in intensity than the FIII peak owing to the alternating tendency in this copolymeriza- tion. However, the two peaks at 8.66 and 8.71 $\tau$ were found to have almost equal intensities in all the spectra obtained. Thus, the latter explanation is rejected, and the former is accepted.

It should be noted that the methyl resonance in IIF is a singlet, while that in FII is a doublet. This means that the influence of the asymmetric center is so strong in the structure 1 that the nonequivalence of the methyl groups can be observed, but that in the structure 2 the influence is not so strong for the nonequivalence to be detected.<smiles>CC(C)(C)CC(Cl)Cl</smiles><smiles>CC(Cl)=[Cr]C(C)(C)C</smiles>

The spacing of the doublet assigned to FIF is about $16 \mathrm{~Hz}$ and is much larger than that $(5 \mathrm{~Hz})$ of the doublet attributed to FII. This gives the evidence that both types of asymmetric centers 1 and 2 participate in causing the nonequivalence of the central methyl groups in the

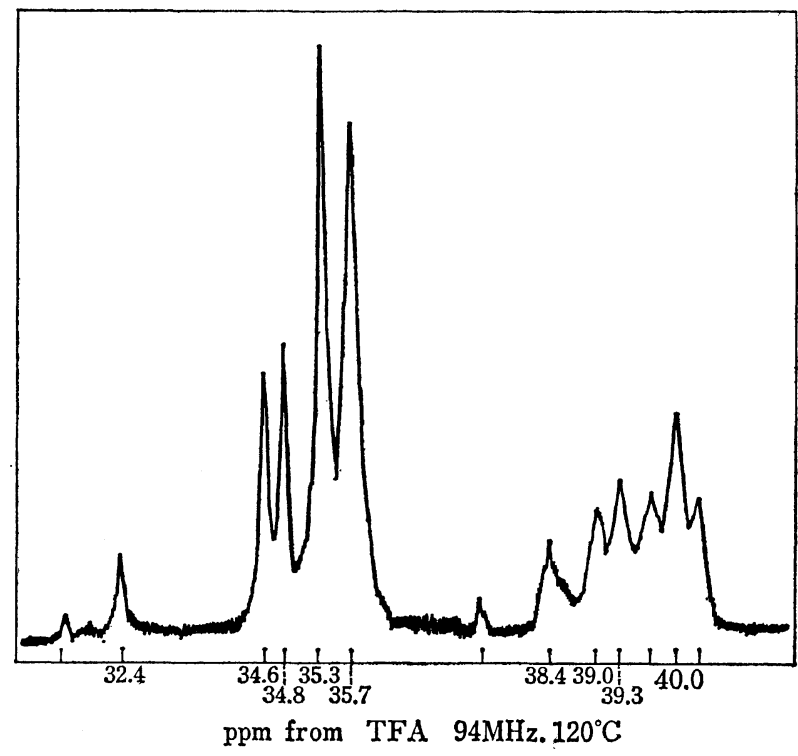

Figure 2. A 94- $\mathrm{MHz}$ fluorine spectrum of a copolymer with $0.43 \mathrm{~mol} \%$ of CTFE at $120^{\circ} \mathrm{C}$. 
FIF triad, and suggests that the copolymer is stereospecific (probably isotactic) as already discussed in a previous paper. ${ }^{6}$

There is no reason for the splitting of methyl resonance in the III triad, as far as triads are considered. The two peaks assigned to III, however, can be explained if tetrads are taken into account. Thus, the peaks at 8.80 and 8.85 $\tau$ were attributed to IIIF and IIII, respectively. As already mentioned above, the peak IIIF should be stronger in intensity than the peak IIII. But in all the spectra obtained, the intensity of the IIII peak was stronger than that of the peak IIIF, and furthermore, when the copolymerizations are carried out at lower temperatures, the relative intensity of IIII to IIIF tends to increase. It has already been reported ${ }^{5}$ that the polymerization of isobutylene takes place independently via a cationic mechanism at lower temperatures in the isobutylene-tetrafluoroethylene system, and that the methyl resonance of polyisobutylene appears at $8.85 \tau$. Therefore, it is concluded that the homopolymer of isobutylene is responsible for most of the IIII peak.

In Figure 2 is indicated a typical 94-MHz. ${ }^{19} \mathrm{~F}$ spectrum of a copolymer deviated from the alternating structure. In a previous paper, ${ }^{6}$ it was reported that the spectrum of the alternating copolymer was composed of an AB-type quartet centered at about $35.5 \mathrm{ppm}$ and a triplet at 40.0 ppm from trifluoroacetic acid as a reference, which was assigned to the $\mathrm{CF}_{2}$ and the $\mathrm{CFCl}$ resonances, respectively. There appears an additional quartet at the lower field $(31.7,34.6,34.8$, and $37.6 \mathrm{ppm}$ ) and two extra peaks at 39.0 and $39.3 \mathrm{ppm}$ in the present spectrum. These new peaks are explained in terms of tetrads on the analogy of tetrafluoroethylene-isobutylene copolymers, and the assignment is given in Table II. Here all the chlorotrifluoroethylene units are assumed to be isolated from one another in the copolymer, which is consistent with the

Table II. Assignment of fluorine resonances

\begin{tabular}{cccc}
\hline Resonance & Structure & Pattern & \multicolumn{1}{c}{ Position, ppm } \\
\hline $\mathrm{CF}_{2}$ & IIFI & Quartet & Centered at 34.7 \\
$\mathrm{CF}_{2}$ & FIFI & Quartet & Centered at 35.5 \\
$\mathrm{CFCl}$ & IFII & Doublet (?) & 39.3 and 39.0 \\
$\mathrm{CFCl}$ & IFIF & Triplet & Centered at 40.0 \\
\hline
\end{tabular}

monomer reactivity ratios of this system $\left(r_{\mathrm{IB}}=\right.$ 0.04 and $\left.r_{\mathrm{CTFE}}=0.00\right)^{9}$

It should be noted that the $\mathrm{CFCl}$ resonance assigned to IFII is not a triplet, but appears to be a doublet. The $\mathrm{CFCl}$ resonances are supposed to be explained as X-parts of $\mathrm{ABX}$ spectra, if vicinal ${ }^{19} \mathrm{~F}-{ }^{19} \mathrm{~F}$ coupling constants are negligibly small as in the present case. The $\mathrm{CFCl}$ resonance appearing at the lower field probably comprises six peaks, that is, two unresolved doublets observed at 39.0 and $39.3 \mathrm{ppm}$ and two weak outer peaks overlapping with neighboring signals. Vicinal ${ }^{19} \mathrm{~F}-{ }^{1} \mathrm{H}$ coupling constants were calculated on this basis as follows.

$$
\begin{aligned}
& \text { IFII }\left|J_{\mathrm{AX}}+J_{\mathrm{BX}}\right|=28 \sim 29 \mathrm{~Hz} \\
& \text { IFIF }\left|J_{\mathrm{AX}}+J_{\mathrm{BX}}\right|=54 \sim 56 \mathrm{~Hz}\left(120^{\circ} \mathrm{C}\right)
\end{aligned}
$$

It is of great interest that the value $\mid J_{\mathrm{AX}}+$ $J_{\mathrm{BX}} \mid$ in IFII is approximately a half of that in IFIF. Since the vicinal coupling constant is remarkably dependent on the internal rotation angle about the related bond, the above result suggests that the substituents on the carbon atoms no. 2 (and probably also of no. 3 ) in the formula 3 affect to a great extent the internal rotation potential about the $\mathrm{CFCl}-\mathrm{CH}_{2}$ bond, and that the spectra are quite sensitive to the conformational structure of the polymer segment.<smiles>CCC(C)(C)C=CCC(C)(C)CC</smiles>

This tempted the authors to investigate the temperature dependence of the spectra, and it was found that the ${ }^{19} \mathrm{~F}$ spectra, above all the $\mathrm{CF}_{2}$ resonances, showed a marked temperature dependence as in Figure 3. The temperature dependence of the related parameters is listed in Table III.

Evidently the values $\left|J_{\mathrm{AX}}+J_{\mathrm{BX}}\right|$ and $\delta_{\mathrm{FFgem}}$ increase with decreasing temperature, while $J_{\mathrm{FFg} e m}$ is almost constant or decreases slightly with decreasing temperature. The value $\left|J_{\mathrm{AX}}+J_{\mathrm{BX}}\right|$ seems to be rather large in IFIF since the vicinal ${ }^{19} \mathrm{~F}-{ }^{1} \mathrm{H}$ coupling constant is usually not larger than $30 \mathrm{~Hz} .^{10}$ However, it is known that the vicinal coupling constant between ${ }^{19} \mathrm{~F}$ and ${ }^{1} \mathrm{H}$ is quite sensitive to the dihedral angle between the 


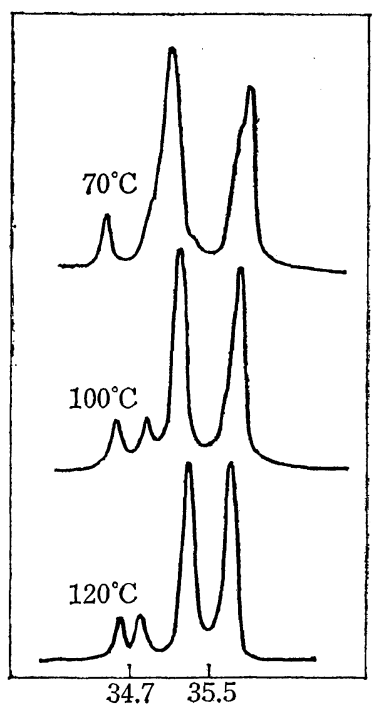

Figure 3. Temperature dependence of the central doublet of the $\mathrm{CE}_{2}$ resonances $(94 \mathrm{MHz}$ ).

Table III. Temperature dependence of the related parameters

\begin{tabular}{|c|c|c|c|c|}
\hline \multirow{2}{*}{ Temp, ${ }^{\circ} \mathrm{C}$} & \multirow{2}{*}{$\begin{array}{c}\left|J_{\mathrm{AX}}+J_{\mathrm{BX}}\right|, \\
\mathrm{Hz} \text { IFIF }^{\mathrm{a}}\end{array}$} & \multicolumn{2}{|c|}{$\delta_{\mathrm{FF} g e m}^{b}, \mathrm{~Hz}$} & \multirow{2}{*}{$\underbrace{\mathrm{FIFI}^{\mathrm{c}}}_{\mathrm{FIF}^{\mathrm{c}}}$} \\
\hline & & FIFI $^{a}$ & IIFI $^{a}$ & \\
\hline 120 & 55 & 153 & 113 & 265 \\
\hline 100 & 60 & 131 & 140 & 263 \\
\hline 70 & 72 & 211 & 154 & 258 \\
\hline
\end{tabular}

a Signals from which the parameters ware calculated.

b $\delta_{\mathrm{FF} \text { gem }}$, difference of chemical shifts between the geminal fluorine atoms.

c $J_{\mathrm{FF} g e m}$, geminal ${ }^{19} \mathrm{~F}-{ }^{19} \mathrm{~F}$ coupling constant.

CCF plane and the $\mathrm{CCH}$ plane. Bovey, et al., ${ }^{11}$ observed the high value of $43.5 \mathrm{~Hz}$ as a vicinal ${ }^{19} \mathrm{~F}-{ }^{1} \mathrm{H}$ coupling constant for a trans conformation in cyclohoxyl fluoride, and Gutowsky, et $a l .,{ }^{12}$ found that $J_{\mathrm{HFtrans}}$ is about $37.3 \mathrm{~Hz}$ in a substituted fluoroalkane.

It is very interesting to note the difference between the values of $\delta_{\mathrm{FF} g}$ calculated from the FIFI and IIFI signals. It was deduced in a previous paper ${ }^{6}$ that the two geminal ${ }^{19} \mathrm{~F}$ nuclei become nonequivalent under the influence of the asymmetric center at the nearest neighboring position and that the effect of the third neighboring asymmetric carbon might be negligible. The above result, however, shows that the effect of the nearest neighboring asymmetric center is strong enough to cause the geminal fluorine nuclei te be nonequivalent, and furthermore, that the contribution of the asymmetric carbon at the third neighboring position is not negligible because it evidently enhances the nonequivalence of the geminal fluorines.

According to Price, the sequence distribution in copolymers can be treated by means of Markoffian statistics. If third order Markoffian statistics $^{13}$ are applied to the present system as in a previous paper, ${ }^{5}$ the following relations are obtained.

$$
\begin{aligned}
& V_{\mathrm{IIF}}=V_{\mathrm{FII}} \\
& V_{\mathrm{FFI}}=V_{\mathrm{IFF}} \\
& V_{\mathrm{IIF}}+V_{\mathrm{FIF}}=V_{\mathrm{IFI}}+V_{\mathrm{IFF}}
\end{aligned}
$$

where $V_{\text {IIF }}, V_{\text {FII }}, V_{\text {FFI }}$, etc., refer to the relative concentrations of the corresponding triad components. In the present case,

$$
V_{\mathrm{FFF}}=V_{\mathrm{FFI}}=V_{\mathrm{IFF}}=0
$$

If $\boldsymbol{P}_{\mathrm{III} / \mathrm{I}}, \boldsymbol{P}_{\mathrm{IFT} / \mathrm{I}}$, and $\boldsymbol{P}_{\mathrm{FII} / \mathrm{I}}$ are defined as the probabilities with which the growing chains with the respective end groups III, IFI, and FII add to an isobutylene monomer, then, $V_{\mathrm{III}}, V_{\mathrm{IIF}}$, $V_{\text {FII }}, V_{\mathrm{IFI}}$, and $V_{\mathrm{FIF}}$ are expressed by using these probabilities as in the eq $8-11$.

$$
\begin{aligned}
& V_{\mathrm{III}}=-C P_{\mathrm{IFI} / \mathrm{I}} P_{\mathrm{FII} / \mathrm{I}} \\
& V_{\mathrm{IIF}}=V_{\mathrm{FII}}=-C P_{\mathrm{IFI} / \mathrm{I}}\left(1-P_{\mathrm{III} / \mathrm{I}}\right) \\
& V_{\mathrm{IFI}}=-C\left(1-P_{\mathrm{III} / \mathrm{I}}\right) \\
& V_{\mathrm{FIF}}=-C\left(1-P_{\mathrm{III} / \mathrm{I}}\right)\left(1-P_{\mathrm{IFI} / \mathrm{I}}\right)
\end{aligned}
$$

where $C$ is a constant value. From these relations the eq 12 and 13 are obtained.

$$
\begin{gathered}
\frac{V_{\mathrm{IIF}}}{V_{\mathrm{IFI}}}=P_{\mathrm{IFI} / \mathrm{I}}=\frac{r_{\mathrm{IFI}} M_{\mathrm{I}}}{M_{\mathrm{F}}+r_{\mathrm{IFI}} M_{\mathrm{I}}} \\
\frac{V_{\mathrm{III}}}{V_{\mathrm{IIF}}}=\frac{P_{\mathrm{FII} / \mathrm{I}}}{1-P_{\mathrm{III} / \mathrm{I}}} \\
=\left(\frac{M_{\mathrm{I}}}{M_{\mathrm{F}}}\right)\left(\frac{M_{\mathrm{F}}+M_{\mathrm{I}} r_{\mathrm{III}}}{M_{\mathrm{F}}+M_{\mathrm{I}} r_{\mathrm{FII}}}\right) r_{\mathrm{FII}}
\end{gathered}
$$

where $M_{\mathrm{I}}$ and $M_{\mathrm{F}}$ are the mole fractions of isobutylene and chlorotrifluoroethylene in the monomer mixture, respectively, and $r_{\mathrm{FFI}}, r_{\mathrm{III}}$, and $r_{F I I}$ are the relative reactivity ratios defined 
by the eq 16 , etc.,

$$
\begin{gathered}
\cdots \mathrm{IFI}+\mathrm{I} \stackrel{k_{\mathrm{IFI} / \mathrm{I}}}{\longrightarrow} \cdots \mathrm{FII} \\
r_{\mathrm{IFI}}=\frac{k_{\mathrm{IFI} / \mathrm{I}}}{k_{\mathrm{IFI} / \mathrm{F}}}
\end{gathered}
$$

The eq 13 is rewritten as follows.

$$
\begin{aligned}
& a^{2} u\left(\frac{1}{r_{\mathrm{FII}}}\right)-r_{\mathrm{III}}=a(1-u) \quad(17) \quad \text { and } 20 . \\
& m_{\mathrm{F}}=\frac{V_{\mathrm{IFF}}+V_{\mathrm{FFI}}+V_{\mathrm{IFI}}+V_{\mathrm{FFF}}}{V_{\mathrm{III}}+V_{\mathrm{IIF}}+V_{\mathrm{IFI}}+V_{\mathrm{FII}}+V_{\mathrm{IFF}}+V_{\mathrm{FIF}}+V_{\mathrm{FFI}}+V_{\mathrm{FFF}}}=V_{\mathrm{IFI}}
\end{aligned}
$$

\begin{tabular}{|c|c|c|c|c|c|c|c|c|}
\hline \multirow{2}{*}{ No. } & \multirow{2}{*}{$\begin{array}{l}\text { CTFE, mol \% } \\
\text { in monomer } \\
\text { mixture } M_{\mathrm{F}}\end{array}$} & \multirow{2}{*}{$\begin{array}{c}\text { Conversion, } \\
\%\end{array}$} & \multirow{2}{*}{$\begin{array}{l}\text { CTFEa, } \\
\text { mol \% in } \\
\text { copolymer }\end{array}$} & \multicolumn{5}{|c|}{$V, \%$} \\
\hline & & & & FIF & IIF & FII & III $^{\mathrm{b}}$ & $\mathrm{IFI}^{\mathrm{c}}$ \\
\hline A & 7.6 & 13.7 & 35.9 & 23.6 & 14.5 & 15.6 & 8.2 & 38.1 \\
\hline B & 10.9 & 20.8 & - & 25.0 & 14.6 & 14.9 & 5.9 & 39.7 \\
\hline C & 12.8 & 17.1 & - & 29.2 & 12.4 & 12.9 & 4.0 & 41.6 \\
\hline D & 14.0 & 13.6 & 39.3 & 29.2 & 12.2 & 12.6 & 3.2 & 42.2 \\
\hline $\mathrm{E}$ & 17.0 & 15.3 & - & 31.8 & 11.6 & 11.0 & 2.4 & 43.2 \\
\hline $\mathrm{F}$ & 19.6 & 18.5 & - & 33.0 & 10.6 & 11.0 & 1.9 & 43.5 \\
\hline G & 23.4 & 17.6 & 45.2 & 40.6 & 6.0 & 6.2 & 1.0 & 46.2 \\
\hline $\mathrm{H}$ & 74.4 & 12.2 & 49.0 & 47.2 & 1.6 & 1.7 & 0.9 & 48.7 \\
\hline
\end{tabular}

Table IV. Relative concentrations of the trial components

a CTFE concentrations in the copolymers were determined from elemental analyses.

b $V_{\mathrm{III}}(\%)$ was determined as the sum of $V_{\mathrm{IIIF}}$ and $V_{\mathrm{IIII}}^{*}$, where $V_{\mathrm{IIII}}^{*}$ was calculated according to the following equation, assuming $r_{\mathrm{III}}=0.04$.

$\frac{V_{\text {IIII }}^{*}}{V_{\text {IIIF }}}=\frac{V_{\text {III }} P_{\text {III } / \mathrm{I}}}{V_{\text {III }} P_{\text {III } / \mathrm{F}}}=\frac{P_{\text {III } / \mathrm{I}}}{1-P_{\text {III } / \mathrm{I}}}=r_{\mathrm{III}} \frac{M_{\mathrm{I}}}{M_{\mathrm{F}}}$

- $V_{\mathrm{IFI}}$ was calculated in accordance with the eq 6 .

$$
\begin{gathered}
\frac{V_{\mathrm{IIFI}}}{V_{\mathrm{FIFI}}}=\frac{V_{\mathrm{IIF}} P_{\mathrm{IIF} / \mathrm{I}}}{V_{\mathrm{FIF}} P_{\mathrm{FIF} / \mathrm{I}}}=\frac{V_{\mathrm{IIF}}}{V_{\mathrm{FIF}}} \\
\frac{V_{\mathrm{IFII}}}{V_{\mathrm{IFIF}}}=\frac{V_{\mathrm{IFI}} \boldsymbol{P}_{\mathrm{IFI} / \mathrm{I}}}{V_{\mathrm{IFI}} P_{\mathrm{IFI} / \mathrm{F}}}=\frac{\boldsymbol{P}_{\mathrm{IFI} / \mathrm{I}}}{1-\boldsymbol{P}_{\mathrm{IFI} / \mathrm{I}}}=r_{\mathrm{IFI}} \frac{M_{\mathrm{I}}}{M_{\mathrm{F}}}
\end{gathered}
$$

In Table IV the relative concentrations of the triads are shown together with the polymerization conditions. According to the eq 2, $V_{\text {IFI }}$ should be equal to $V_{\text {FII }}$, and a fairly good agreement is obtained between the experimental results and the theory. The chlorotrifluoroethylene contents of the copolymers determined from elemental analyses seem to be a little lower than those obtained from NMR data $\left(V_{\mathrm{IFI}}\right)$ in the samples polymerized at the lower chlorotrifluoroethylene
Table V. Verifications of the equations

\begin{tabular}{cccc}
\hline \multirow{2}{*}{ No. } & $V_{\text {IIFI }}$ & $\frac{V_{\text {IIF }}}{n}$ & $r_{\text {IFI }}{ }^{\mathrm{a}}$ \\
\cline { 2 - 4 }$V_{\text {FIFI }}$ & $V_{\text {FIF }}$ & \\
\hline A & 0.64 & 0.68 & 0.040 \\
B & 0.58 & 0.58 & 0.053 \\
C & 0.44 & 0.43 & 0.048 \\
D & 0.42 & 0.41 & 0.058 \\
E & 0.34 & 0.36 & 0.065 \\
F & 0.31 & 0.32 & 0.065 \\
G & 0.18 & 0.15 & 0.040 \\
H & $\sim 0$ & 0.03 & - \\
\hline
\end{tabular}

a Calculated from the eq 12.

concentrations in the monomer mixtures. Probably this is due to the fact that the values in 
the NMR data contain the contribution of neither polyisobutylene nor the end groups of the polymer chains.

The relative intensity ratio of tetrads, $V_{\mathrm{IIFI}} /$ $V_{\text {FIFI }}$, which was determined from the ${ }^{19} \mathrm{~F}$ spectra, is almost equal to that of triads, $V_{\text {IIF }} / V_{\text {FIF }}$, obtained from the methyl resonances, as shown in Table V. This agreement suggests that the present copolymerization reaction is expressed in terms of a third or lower order Markoff process. A plot of $a(1-u) v s . a^{2} u$ is given in Figure 4,

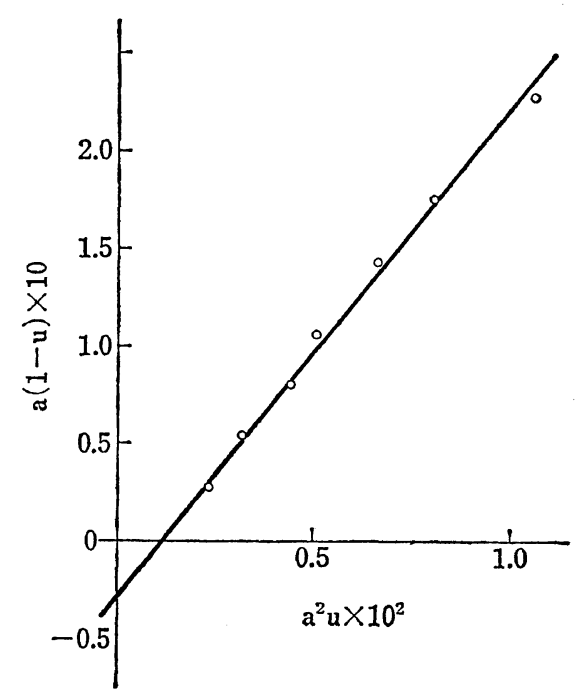

Figure 4. A plot of $a(1-u) v s . a^{2} u$.

where the mean values of the initial and final concentrations are used as $M_{\mathrm{F}}$ and $M_{\mathrm{I}}$. The plot gives a straight line, from which $r_{I I I}$ and $\boldsymbol{r}_{\mathrm{FII}}$ are determined as follows.

$$
\begin{aligned}
& r_{\text {III }}=0.030 \\
& r_{\text {FII }}=0.038
\end{aligned}
$$

On the other hand, the value of $r_{I F I}$ in Table $\mathrm{V}$ is somewhat scattered, and it may be difficult to derive a decisive conclusion from these data. However, when $r_{I I I}$ and $r_{F I I}$ are compared with values of $r_{\mathrm{IFI}}$, it appears that although the difference between the values of $r_{\mathrm{III}}$ and $r_{\mathrm{FII}}$ is meaningless, the value of $r_{\mathrm{IFI}}$ is clearly different from the values of $r_{\mathrm{III}}$ and $r_{\mathrm{FII}}$. This means that the present copolymerization reaction is expressed as a second order Markroff process, or that there exists a penultimate effect in this copolymerization reaction.

\section{REFERENCES}

1. R. C. Ferguson, J. Amer. Chem. Soc., 82, 2416 (1960).

2. R. E. Naylor, Jr., and S. W. Lasoski, Jr., J. Polym. Sci., 44, 1 (1960).

3. C. W. Wilson III and E. R. Santee, J. Polym. Sci., Part C, 8, 97 (1965).

4. G. V. D. Tiers and F. A. Bovey, J. Polym. Sci., Part A, 1, 833 (1963).

5. K. Ishigure and Y. Tabata, Macromolecules, 3, 450 (1970).

6. K. Ishigure, Y. Tabata, and K. Oshima, Macromolecules, 3, 27 (1970).

7. J. N. Shoolery and M. T. Rogers, J. Amer. Chem. Soc., 80, 5121 (1958).

8. A. H. Lewin, J. Lipowitz, and T. Cohen, Tetrahedron Letters, 1965, 1241.

9. K. Ishigure, Y. Tabata, and K. Oshima, $J$. Macromol. Sci., A5(2), 263 (1971).

10. F. A. Bovey, "Nuclear Magnetic Resonance Spectroscopy," Academic Press, New York, N.Y., 1969 p 221.

11, F. A. Bovey, E. W. Anderson, F. P. Hood, and R. L. Kornegay, J. Chem. Phys., 40, 3099 (1964).

12. H. S. Gutowsky, G. G. Belford, and P. E. MacMahon, J. Chem. Phys., 39, 3353 (1962).

13. F. P. Price, J. Chem. Phys., 36, 209 (1962). 